\title{
Allele loss on chromosome 3 in squamous cell carcinoma of the head and neck correlates with poor clinical prognostic indicators
}

\author{
JOHN K. FIELD ${ }^{1}$, CHRISTOS TSIRIYOTIS ${ }^{1,2}$, VASILIS ZOUMPOURLIS ${ }^{1,2}$, PETER HOWARD $^{3}$, \\ DEMETRIOS A. SPANDIDOS ${ }^{2,4}$, ANDREW S. JONES ${ }^{5}$
}

\author{
${ }^{1}$ Department of Clinical Dental Sciences, The University of Liverpool, PO Box 147, Liverpool L69 3BX; \\ ${ }^{2}$ National Hellenic Research Foundation, 48 Vas. Constantinou Avenue, Athens 11635 Greece; ${ }^{3}$ Regional Cytogenetic Unit, \\ Royal Liverpool Hospital Trust, Liverpool UK; ${ }^{4}$ Medical School, University of Crete, Heraklion, Greece; \\ ${ }^{5}$ Department of Otorhinolarynology, The University of Liverpool, Liverpool, UK
}

Contributed by D.A. Spandidos, December 23, 1993

\begin{abstract}
Cytogenetic studies in squamous cell carcinoma of the head and neck (SCCHN) have identified a clustering of breakpoints in a number of chromosomes, including chromosome 3 . We have undertaken a loss of heterozygosity analysis ( $\mathrm{LOH})$ of $36 \mathrm{SCCHN}$ and six solid tumours which were not squamous cell, and their respective normal specimens, using a bank of microsatellite markers, with the aim of identifying specific sites of frequent loss on chromosome 3 . The analysis was undertaken with 12 microsatellite markers, 10 of which are on the p arm of chromosome 3. Allelic loss greater than $10 \%$ was seen at four sites; D3S1269 (13\%), D3S1079 (23\%), D3S659 (23\%) and D3S1293 (31\%). None of this series of tumours showed loss of the whole chromosome, however $47 \%$ of the tumours analysed had LOH at one or more loci. The highest incidence of $\mathrm{LOH}$ was found at D3S1293 in the 3p24-p25 region. The second highest region with $\mathrm{LOH}$ was found at D3S1079 and D3S659 at 3p13. The remaining markers telomeric and centromeric to these two regions were found to have a $\mathrm{LOH}$ of less than $10 \%$. Furthermore, we found a strong association between loss of one marker on chromosome 3 in these SCCHN and poor clinical prognostic indicators; such as site, pathological differentiation, positive nodes at pathology $(\mathrm{p}<0.05)$ and TNM status $(\mathrm{p}<0.05)$. This study has identified two regions in SCCHN that are most likely to be important in the development of squamous cell carcinoma of the head and neck at 3p24-p25 and 3p13 and may indicate sites of novel tumour suppressor genes in this disease.
\end{abstract}

\section{Introduction}

Loss of heterozygosity ( $\mathrm{LOH}$ ) for polymorphic DNA markers have already provided a wealth of information on

Correspondence to: Dr John K. Field, Department of Clinical Dental Sciences, The University of Liverpool, PO Box 147, Liverpool L69 3BX, UK

Key words: Allele loss; microsatellites; chromosome 3; head and neck cancer; prognosis chromosomal imbalances which would have been difficult if not impossible to obtain from cytogenetic evidence (reviewed by Lasko et al; 1). Specific sites of frequent allele loss has been described in a number of malignancies such as; carcinomas of the colon $(2,3)$, ovarian (4-6), colorectal, bladder (7-8), and breast carcinomas (9) and tumour suppressor genes (TSG) have been suggested to be involved at many of these regions.

Cytogenetic studies in squamous cell carcinoma of the head and neck SSCHN has identified a clustering of breakpoints in a number of chromosomes, including chromosome 3. Jin et al (10) found a high incidence of chromosomal breakpoints at $1 \mathrm{p} 22$ and $11 \mathrm{q} 13$, whereas other groups have found 1p36, 9q32, 11q23, (11) 3p, 8q, 10p, 18q, (12), 3p13-14, 8p21-23 and 18q21-23 (Van Dyke DL, Worsham MJ, Benninger MJ and Carney TE: 5th International Workshop on chromosomes in solid tumours, Arizona, 1993). However, there are many limitations to the interpretation of cytogenetic analysis of head and neck cancers as the majority of the chromosomes have been found to be involved $(10,11)$. Latif et al (13) have used a bank of restriction fragment length polymorphism (RFLP) probes, and generated a $3 p$ allelotype for 18-26 SSCHN cell lines. Their observations indicated that there was a commonly deleted region on $3 p$ which lies telomeric to $3 p 14$ and centromeric to $3 p 25$. Furthermore, in a cytogenetic analysis of 15 laryngeal tumours, a deletion in 3p was found in $60 \%$ of the cases analysed (14). This region of the chromosome has received a great deal of interest in a number of malignancies resulting in the mapping of the Von HippelLindau TSG to 3p25-26, small cell lung carcinoma genes to 3p23-p21, non-small cell carcinoma gene to $3 p 14$, uterine cervix gene to $3 \mathrm{p} 14-\mathrm{p} 21$ and renal cell carcinomas to $3 \mathrm{p} 14.2$ (15).

The development of banks of microsatellite markers has now advanced the analysis of LOH studies $(16,17)$. The microsatellites constitute one of the most abundant classes of repetitive DNA families in the human genome with approximately $100,000-150,000(\mathrm{CA})_{\mathrm{n}}$ repeats, and have been used extensively in linkage analysis (18) and are probably more sensitive than RFLP analysis. 
We have investigated chromosome 3 in SCCHN with 12 microsatellite markers in order to determine the incidence of LOH especially on the $\mathrm{p}$ arm of chromosome 3 and evaluate the results with the clinicopathological data.

\section{Materials and methods}

Forty-two tumour specimens were collected from patients with carcinomas of the head and neck by the Royal Liverpool Hospital, Department of Otorhinolaryngology (36 SCCs; hypopharynx (18), larynx (11), oropharynx (4) oral (2), and 2 basal cell carcinomas, a malignant salivary tumour, a Warthins tumour, a chondroma and a neurosarcoma were selected for this study. Tumour samples obtained from surgical specimens were frozen in liquid nitrogen and stored at $-70^{\circ} \mathrm{C}$.

Frozen sections were taken from representative parts of the tumour and stained with haematoxylin and eosin and the percentage of tumour to normal tissue was recorded. All tumour specimens used in this study contained more than $50 \%$ tumour tissue compared with normal tissue. Clinicopathological and survival data was available for the majority of the patients investigated in this study.

DNA extraction. Genomic DNA was extracted from tumour specimens using the Nucleon II DNA extraction kit from Scotlab, following the manufacturers instructions. Genomic DNA samples were stored at $4^{\circ} \mathrm{C}$.

Microsatellite repeat primers. The markers used in this study are shown in Table I. and their chromosomal location in Fig. 1. The Weissenback markers have been localised on the genetic map using all available published data to date. The microsatellite primers D3S1261, D3S1266, D3S1269, D3S1289, D3S1293, D3S1340 were obtained from Research Genetics, USA; D3S966, D3S1067, D3S1079 from the UK Human Genome Mapping Project; D3S1284 from Professor P. Humpheries University of Dublin; D3S659, RHO from Dr Pamela H. Rabbitts, University of Cambridge. The annealing temperature for each marker is given in Table I. Details of the microsatellite primers are available in the Genome Data Base, John Hopkins University, USA and from the UK Human Genome Mapping Project Research Centre, and Jones et al (19).

LOH analysis. PCR reactions were performed in a $50 \mu 1$ reaction volume and contained $200 \mathrm{ng}$ of genomic DNA, 500 $\mu \mathrm{M}$ dNTP, 10 pmoles of each forward and reverse microsatellite primers, 0.5 units of Taq DNA polymerase (Advanced Biotechnologies), $5 \mu 1$ of 10X PCR Buffer (670 $\mathrm{mM}$ Tris. $\mathrm{HCl}, \mathrm{pH} 8.5 ; 166 \mathrm{mM}$ ammonium sulphate; $67 \mathrm{mM}$ magnesium chloride; $1.7 \mathrm{mg} / \mathrm{ml}$ BSA; $100 \mu \mathrm{M} \mathrm{B-}$ mercaptoethanol; $1 \%(\mathrm{w} / \mathrm{v})$ Triton $\mathrm{X}-100)$. The reactions were denatured for 4 minutes and the DNA was subsequently amplified for 25 cycles of $94^{\circ} \mathrm{C}$ for 30 seconds, the appropriate primer annealing temperature (Table I) for 30 seconds and $72^{\circ} \mathrm{C}$ for 1 minute. $10 \mu$ of the amplified PCR reaction mixture was electrophoresed overnight on a $10 \%$ acrylamide gel at $20 \mathrm{~mA}$ for $2500 \mathrm{~V} \mathrm{~h}$. The acrylamide gels were silver-stained and the DNA bands observed over a light box.
Statistical analysis. Quantative data were analysed by $\mathrm{X}^{2}$ or Fisher's exact test where appropriate. Survival curves were drawn up using the Kaplan-Meier product limit estimate (20). Differences between survival times were analysed by the log rank method (21).

\section{Results}

We analysed 36 SCCHN and 6 non squamous tumours from the head and neck regions for $\mathrm{LOH}$ at 10 different loci on chromosome $3 p$ and 2 loci on $3 q$ using PCR microsatellite pairs. The $\mathrm{LOH}$ results are shown in Table II for all the patients (Pts) analysed, and the LOH frequencies at each locus are shown in Table III. Loss of heterozygosity is demonstrated in Pt. 343 at the D3S1293, D3S966, D3S1067 and D3S1079 loci; heterozygous at the D3S1304 and D3S1269 loci and homozygous at the RHO locus (Fig. 2).

Allele loss greater than $10 \%$ was seen at four loci, D3S 1269 (13\%, 4/30); D3S1079 (23\% 5/22); D3S659 (23\%/6/26) and D3S1293 (31\% 9/29). In this series of. SCCHN, none of the tumour specimens showed whole chromosome loss, however $47 \%(17 / 36)$ of the tumours analysed had $\mathrm{LOH}$ at one or more loci.

The highest incidence of loss of heterozygosity was found at D3S1293 (31\%) in the 3p24-25 region. No LOH was found at D3S1266 in 36 specimens of SCCHN, which has been localised to the 3p24 region centromeric to D3S1293. The Weissenbach et al, 1992 map indicates a 9cM distance between these two microsatellite markers. It is improbable that there is a large deletion at this site, as only two of these patients $(327,341)$ had LOH at D3S1289, which is $30 \mathrm{cM}$ centromeric to D3S1293. It is of note that in five cases (Pts. $217,327,338,343,347)$ there is also loss at D3S1079 as well as D3S1293 and both of these markers are located at 3p13. Futhermore, the D3S1304 marker is $19 \mathrm{cM}$ telomeric to D3S1293 and only 7\% of the SCCHN specimens had LOH at this locus.

The clinicopathological data has been analysed in conjunction with the LOH results, for site, TNM stage, histological differentiation, positive nodes at pathology and survival. A clear association has been found between $\mathrm{LOH}$ on chromosome 3 and squamous cell carcinoma (SCC) at the hypopharyngeal site $58 \%$ (11/19), compared to $36 \%(4 / 11)$ $\mathrm{LOH}$ at the laryngeal site. Furthermore, an association between $\mathrm{LOH}$ on chromosome 3 and a poor clinical prognosis as judged by the level of differentiation, positive nodes at pathology and TNM staging has been found (Tables IV and V).

Analysis of $\mathrm{LOH}$ on chromosome 3 and histological differentiation demonstrated an increase in the incidence of allelic loss with the level of differentiation; well differentiated $20 \%$, moderately differentiated $48 \%$ and poorly differentiated squamous cell carcinoma $83 \%$, but this was not found to be statistically significant as the numbers of patients in certain groups were small $(p>0.05)$. However, a dramatic increase in the number of positive nodes at pathology was seen to correlate with LOH; SCCHN with no lymph nodes had $21 \%$ LOH, whereas SCCHN with positive lymph nodes had 63\% $\mathrm{LOH}(\mathrm{p}<0.05)$. This trend with LOH on chromosome 3 with poor prognostic factors is further supported by an association with TNM staging of the tumours. Stages I, II, III had 33\% 


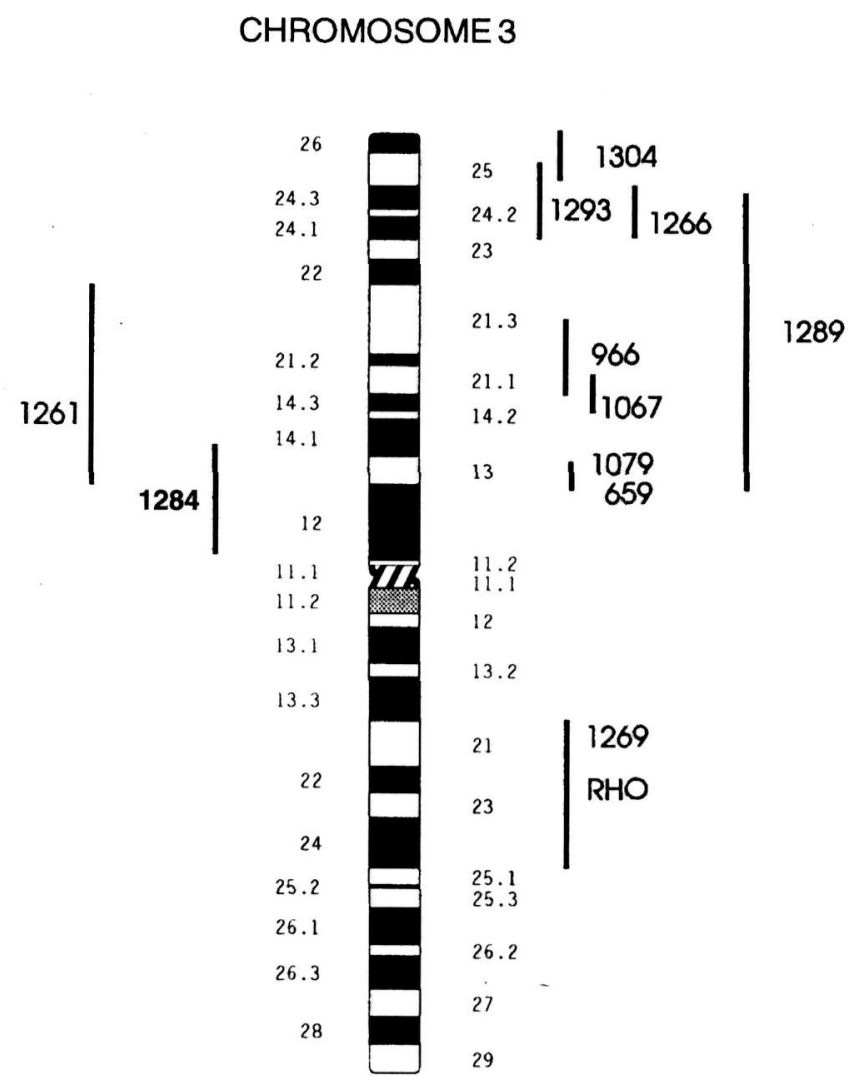

Figure 1. A karyogram of chromosome 3. The microsatellite marker loci are shown adjacent to their approximate map position based on previously published data and the $\mathrm{LOH}$ analysis in this study.

(7/22) LOH compared to Stage IV, which had 77\% (10/13) LOH $(\mathrm{p}<0.05)$. No correlations with survival data was found, however the follow-up for a number of these patients has been less than six months.

Six other solid tumours of the head and neck region which were not squamous cell were also investigated and only one of these, a BCC had LOH at one locus (results not shown).

\section{Discussion}

In this study we have investigated loss of heterozygosity in 36 SCCHN tumour specimens on chromosome 3 using a bank of microsatellite markers, the majority of which are on the $3 p$ arm. We have identified one region with a high LOH (31\%) using the D3S1293 marker which is located in the 3p24-25 region. In view of the fact that the markers centromeric (D3S1266) and telomeric (D3S1304) to D3S1293 were found to have low LOH, argues strongly in favour of this locus being a possible site of a novel tumour suppressor gene in SCCHN.

A region on chromosome 3p, 3p14 (D3S3) to $3 p 25$ (RAF1) has been previously identified in SCCHN cell lines to have high allelic loss (13). These authors used novel statistical analysis to determine the importance of $\mathrm{LOH}$ on $3 p$. They generated an SCCHN alleotype of $3 p$ using a number of SCCHN cell lines with RFLP markers and then

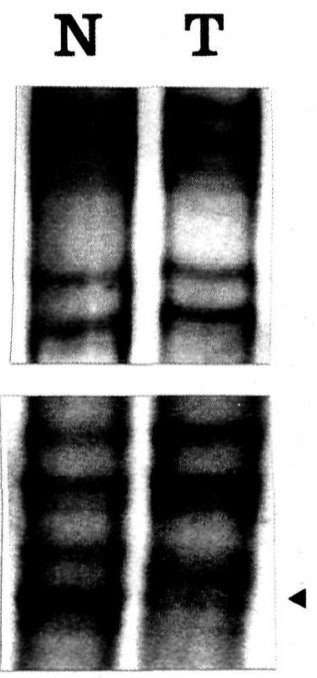

1304

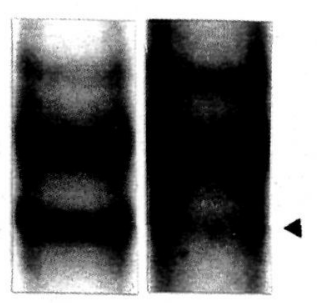

1293

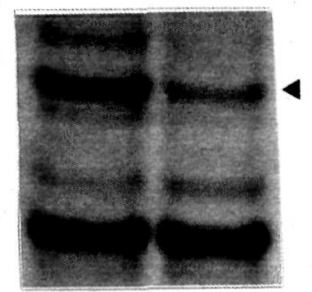

966

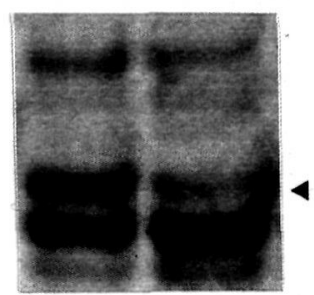

1067

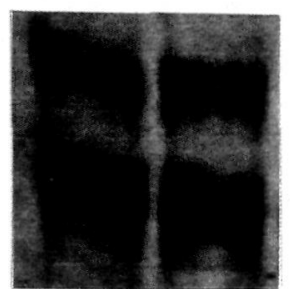

1079

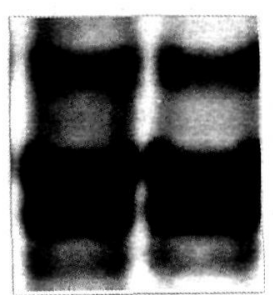

$\mathrm{RHO}$

Figure 2. LOH on chromosome 3, detected by PCR analysis of microsatellite loci in tumour 343 , seven of the microsatellite markers are shown in this figure; D3S1304 heterozygous, D3S1293 LOH, D3S966 LOH, D3S 1067 LOH, D3S 1079 LOH, D3S 1269 heterozygous, RHO homozygous. Note the examples of a heteroduplex band (top band) and the stutter bands seen for both the alleles in D3S1067. 
Table I. Microsatellite repeat primers used in this study of loss of heterozygosity on chromosome 3 in head and neck squamous cell carcinomas.

\begin{tabular}{llll}
\hline Microsatellite primers & Map position & Futher information on map position* & Annealing temperature \\
\hline D3S1304 ${ }^{\mathrm{W}}$ & $3 \mathrm{p} 25-\mathrm{pter}$ & $19 \mathrm{cM}$ telomeric from D3S1293 & $55^{\circ} \mathrm{C}$ \\
$\mathrm{D} 3 \mathrm{~S} 1293^{\mathrm{W}}$ & $3 \mathrm{p} 24-\mathrm{p} 25$ & $\begin{array}{l}\text { located telomeric to } \mathrm{pBH} 302-\mathrm{H} / \mathrm{THRB} . \\
9 \mathrm{cM} \text { from D3S1266 }\end{array}$ & $55^{\circ} \mathrm{C}$ \\
& & $\begin{array}{l}\text { in region of CRI-R59-M/D3S12 } \\
\text { D3S1266 }\end{array}$ & $55^{\circ} \mathrm{C}$ \\
D3S1289 & $3 \mathrm{p} 24$ & located midway between CRI-R59-M/3S12 & \\
& {$[3 \mathrm{p} 24]-[3 \mathrm{p} 21.2-\mathrm{p} 13]$} & and CRI-R95-M/D3S13 21 cM centromeric & $62^{\circ} \mathrm{C}$ \\
D3S1261 & & from D3S1266 & $63^{\circ} \mathrm{C}$ \\
D3S966 & $3 \mathrm{p} 21.2-\mathrm{p} 13$ & & $60^{\circ} \mathrm{C}$ \\
D3S1067 & $3 \mathrm{p} 21$ & & $60^{\circ} \mathrm{C}$ \\
D3S1079 & $3 \mathrm{p} 14.3-\mathrm{p} 21.1$ & & $60^{\circ} \mathrm{C}$ \\
D3S659 & $3 \mathrm{p} 13$ & & $50^{\circ} \mathrm{C}$ \\
D3S1284 & $3 \mathrm{p} 13$ & & $58^{\circ} \mathrm{C}$ \\
D3S1269 & $3 \mathrm{~W} 12-\mathrm{p} 13$ & in the region of CRI-C17-M/D3S20 & $57^{\circ} \mathrm{C}$ \\
RHO & $3 \mathrm{q}$ & $7 \mathrm{cM}$ from RHO & $50^{\circ} \mathrm{C}$ \\
\hline
\end{tabular}

*Information taken from Weissenbach et al 1992 ; ${ }^{{ }^{W}}$ Weissenbach marker set (17).

compared the average heterozygosity computed for these loci in randomly chosen individuals from a natural population, with the observed heterozygosity of the tumour cell DNAs. They firstly deduced that there was a general $\mathrm{LOH}$ in the SCCHN cell lines, and then estimated the loss for each individual locus, thereby delimiting the commonly deleted region. A synopsis of their findings are shown in Table VI. It is of note that they found the probability of the markers at 3p24-25, D3S588 and THRB in the SCCHN cell lines (having the same heterozygosity as in normal individuals) to have values of $4 \times 10^{-10}$ and 0.0003 , respectively. Our results substantiate these findings, as the D3S1293 (3p24-25) marker is located telomeric to THRB on the Weissenbach map, therefore it is most likely closely linked to the D3S588 RFLP marker. In addition, a number of markers centromeric to THRB and telomeric to D3S3 also had high probabilities of loss in tumour DNA and Latiff et al (13) defined the whole 3p13-p25 region of particular importance in SCCHN. The results reported in this study are in agreement with the findings of Latiff et al, as our LOH data indicates that there are specific $\mathrm{LOH}$ regions at 3p24-25 and also at 3p13. Both of the markers D3S1079 and D3S659 located at 3p13 demonstrated a LOH of $23 \%$. However, the intervening markers between D3S1293 (3p24-25) and the 3p13 markers all had LOHs of less than $10 \%$, which may be considered background $\mathrm{LOH}$ in tumour specimens. Even though many of the Weissenback markers have not been precisely located to the genetic map, Fig. 1 provides a reasonable assessment of their relative positions based on previously published data and the $\mathrm{LOH}$ analysis results in this study.

A further argument for the presence of two putative TSGs on $3 p$ comes from our clinical correlations with $\mathrm{LOH}$ analysis on chromosome 3 . The clinicopathological parameters used to assess patients outcome were recorded for all of the patients investigated in this study. The most important are site, pathological differentiation, positive nodes at pathology and the TNM status of the tumour at diagnosis. All of these parameters were found to be associated with LOH on chromosome 3. SCCHN at the hypopharyngeal site constituted the largest group of patients studied, of whom $58 \%(11 / 19)$ had lost one or more markers on chromosome 3 , compared with the laryngeal tumours which had $36 \% \mathrm{LOH}$ (4/12) on one or more markers on chromosome 3. Furthermore, the clinical prognosis of SCC at the hypopharyngeal site is considered to have a worse prognosis than the larynx (22).

The candidate genes for 3p24 and 3p13 sites are listed in Table VII, these include CCK, ACT14, IL5RA, RAF1, FRA3A, IMPDH2, THRB, RARB, TOP2B, and RAB5 in the 3 24-pter region. Recent evidence indicates that there may be as many as three TSGs on the p arm of chromosome 3 . Hibi et al (23) have shown that there are three distinct 
Table II. An analysis of 36 SCCHN by PCR microsatellite primers.

\begin{tabular}{|c|c|c|c|c|c|c|c|c|c|c|c|c|c|c|c|c|c|c|c|}
\hline & $H$ & $H$ & $\mathrm{H}$ & $\mathrm{H}$ & $\mathrm{H}$ & $\mathrm{H}$ & $\mathrm{H}$ & $\mathrm{H}$ & $H$ & $\mathrm{H}$ & $\mathrm{H}$ & $\mathrm{H}$ & $\mathrm{H}$ & $\mathrm{H}$ & H & $\mathrm{H}$ & $\mathrm{H}$ & $\mathrm{H}$ & $\mathrm{H}$ \\
\hline & 114 & 128 & 184 & 192 & 218 & 224 & 227 & 302 & 310 & 313 & 314 & 324 & 325 & 329 & 336 & 338 & 340 & 341 & 346 \\
\hline D3S 1304 & c. & 0 & 0 & 0 & . & 0 & . & 0 & . & 0 & 0 & . & 0 & - & 0 & 0 & . & $\bullet$ & 0 \\
\hline D3S1293 & 0 & 0 & - & 0 & 0 & c & - & 0 & 0 & $\oslash$ & 0 & $\varnothing$ & 0 & - & 0 & - & 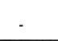 & $\bullet$ & 0 \\
\hline D3S 1266 & 0 & 0 & 0 & 0 & 0 & 0 & 0 & 0 & 0 & 0 & ० & 0 & 0 & 0 & 0 & 0 & 0 & 0 & 0 \\
\hline D3S 1289 & 0 & 0 & 0 & 0 & 0 & 0 & 0 & 0 & $\bullet$ & 0 & 0 & 0 & 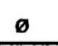 & 0 & 0 & 0 & 0 & $\bullet$ & 0 \\
\hline D3S1261 & 0 & 0 & 0 & 0 & - & $c$ & 0 & 0 & 0 & 0 & 0 & 0 & 0 & $\circ$ & 0 & 0 & 0 & 0 & 0 \\
\hline D3S966 & 0 & 0 & $\bullet$ & 0 & 0 & 0 & 0 & 0 & 0 & 0 & 0 & D & 0 & 0 & 0 & o & 0 & 0 & 0 \\
\hline D3S 1067 & 0 & 0 & . & 0 & 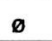 & c & . & 0 & . & ø & 0 & 0 & 0 & $\varnothing$ & 0 & 0 & 0 & 0 & . \\
\hline D3S 1079 & $\oslash$ & 0 & 0 & . & 0 & 0 & . & 0 & 0 & 0 & 0 & 0 & . & 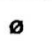 & ø & $\bullet$ & c & 0 & ø \\
\hline D3S659 & $c$ & 0 & $\bullet$ & $\bullet$ & 0 & 0 & - & $\circ$ & 0 & 0 & $\bullet$ & $\bullet$ & . & 0 & 0 & 0 & . &. & $\bullet$ \\
\hline D3S 1284 & 0 & 0 & . & . & . & 0 & . & 0 & . & 0 & 0 & 0 & 0 & 0 & 0 & 0 & 0 & 0 & 0 \\
\hline D3S1269 & 0 & 0 & $\bullet$ & . & - & 0 & $\bullet$ & 0 & $\circ$ & 0 & $\circ$ & 0 & 0 & 0 & 0 & 0 & 0 & $\bullet$ & 0 \\
\hline RHO & . & 0 & . & 0 & . & 0 & . & 0 & . & 0 & $\emptyset$ & 0 & 0 & 0 & D & D & . & 0 & $\oslash$ \\
\hline
\end{tabular}

\begin{tabular}{|c|c|c|c|c|c|c|c|c|c|c|c|}
\hline & L & $L$ & L & L & L & L & $L$ & L & L & L & L \\
\hline & 41 & 76 & 132 & 202 & 213 & 215 & 217 & 223 & 225 & 318 & 347 \\
\hline D3S1304 & 0 & - & . & 0 & - & 0 & . & $\circ$ & 0 & 0 & 0 \\
\hline D3S1293 & 0 & $\bullet$ & 0 & . & 0 & 0 & $\bullet$ & 0 & $\therefore$ & 0 & $\bullet$ \\
\hline D3S1266 & 0 & 0 & 0 & 0 & 0 & 0 & 0 & 0 & 0 & 0 & 0 \\
\hline D3S1289 & 0 & 0 & 0 & 0 & 0 & 0 & $\varnothing$ & 0 & 0 & 0 & 0 \\
\hline D3S1 261 & 0 & $\bullet$ & 0 & 0 & 0 & 0 & 0 & 0 & 0 & 0 & 0 \\
\hline D3S966 & $c$ & $\circ$ & 0 & 0 & 0 & 0 & 0 & 0 & 0 & 0 & 0 \\
\hline D3S1067 & 0 & - & - & 0 & 0 & 0 & $\varnothing$ & $\varnothing$ & $\therefore$ & 0 & 0 \\
\hline D3S 1079 & 0 & . & - & 0 & 0 & $\circ$ & $\bullet$ & $D$ & 0 & 0 & $\bullet$ \\
\hline D3S659 & 0 & . & $\bullet$ & 0 & 0 & 0 & $\bullet$ & 0 & . & 0 & 0 \\
\hline D3S1284 & 0 & . & 0 & ø & 0 & 0 & 0 & 0 & . & 0 & 0 \\
\hline D3S 1269 & 0 & $\emptyset$ & - & . & 0 & 0 & $\bullet$ & 0 & - & 0 & 0 \\
\hline RHO & 0 & . & - & 0 & - & 0 & . & 0 & 0 & 0 & 0 \\
\hline
\end{tabular}

\begin{tabular}{|c|c|c|c|}
\multicolumn{1}{c}{$M$} & $M$ & $M$ & $M$ \\
\hline 315 & 327 & 342 & 348 \\
\hline$\cdot$ & 0 & 0 & 0 \\
\hline 0 & $\bullet$ & 0 & 0 \\
\hline 0 & 0 & 0 & 0 \\
\hline 0 & $\bullet$ & 0 & 0 \\
\hline 0 & 0 & 0 & 0 \\
\hline 0 & 0 & 0 & 0 \\
\hline 0 & 0 & 0 & \\
\hline 0 & $\bullet$ & 0 & 0 \\
\hline 0 & 0 & 0 & 0 \\
\hline 0 & 0 & 0 & 0 \\
\hline 0 & 0 & 0 & 0 \\
\hline$\cdot$ & 0 & 0 & 0 \\
\hline
\end{tabular}

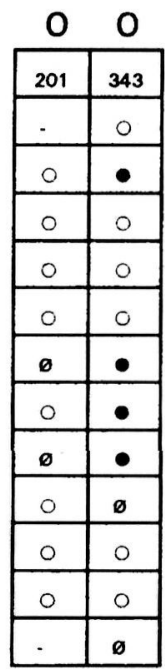

The symbols used are: $\bullet$, constitutional heterozygosity with loss of heterozygosity; o, constitutional heterozygosity with no loss of heterozygosity; Ø, homozygous; not done/not determined; 0, oropharynx; H, hypopharynx; L, larynx and M, oral cavity.

Table III. Loss of heterozygosity on chromosome 3 in head and neck squamous cell carcinomas.

\begin{tabular}{llcr}
\hline Chromosome location & Microsatellite primers & $\begin{array}{c}\text { Number of patients analysed } \\
\text { Allelic loss/ } \\
\text { informative cases }\end{array}$ & $\begin{array}{c}\text { (2/23 (7) } \\
\text { 3p25-pter }\end{array}$ \\
3p24-p25 & D3S1304 & 24 & $9 / 29(31)$ \\
3p24 & D3S1293 & 33 & $0 / 36(0)$ \\
3p24-p13 & D3S1266 & 36 & $3 / 33(9)$ \\
3p21.2-p13 & D3S1289 & 36 & $2 / 33(6)$ \\
3p21 & D3S1261 & 36 & $2 / 28(7)$ \\
3p14.3-p21.1 & D3S966 & 36 & $1 / 17(6)$ \\
3p13 & D3S1067 & 28 & $5 / 22(23)$ \\
3p13 & D3S1079 & 31 & $6 / 26(23)$ \\
3p12-p13 & D3S659 & 30 & $0 / 27(0)$ \\
3q & D3S1284 & 29 & $4 / 30(13)$ \\
3q21-q24 & D3S1269 & 31 & $0 / 14(0)$
\end{tabular}


Table IV. Loss of heterozygosity on chromosome 3 with TNM staging.

\begin{tabular}{lccccc}
\hline Stage & $\begin{array}{l}\text { Loss of one or } \\
\text { two markers }\end{array}$ & $\begin{array}{l}\text { Loss of } 3 \text { or } \\
\text { more markers }\end{array}$ & No loss & LOH/ Heterozygous & Percent \\
\hline I & 2 & 0 & 5 & $2 / 7$ & 28 \\
II & 0 & 0 & 1 & $5 / 1$ & 33 \\
III & 3 & 2 & 10 & $10 / 13$ & 77 \\
IV & 7 & 3 & 3 & 5 & \\
\hline
\end{tabular}

Stages I, II, III with IV, $\mathrm{p}=0.006$

Table V. Loss of heterozygosity on chromosome 3 with histological differentiation and positive nodes at pathology.

Loss of one or more

markers on chromosome 3 No loss Percentage

\section{Histology:}

well differentiated

moderately differentiated

1

10

poorly differentiated
20

48

83

$(\mathrm{p}>0.05)$

positive nodes at pathology:

no nodes

positive nodes

3

10
21

63

$(\mathrm{p}<0.05)$

Table VI. Chromosome $3 p$ deletions in head and neck cell lines. $^{\text {a }}$

\begin{tabular}{lll}
\hline Location on 3p & Locus & Probability* \\
\hline 3 p25 & D3S571 & 0.0038 \\
3 p25 & RAF & 0.0009 \\
3 p24-25 & D3S588 & $4 \times 10^{-10}$ \\
3 p24 & THRB & 0.0003 \\
$3 p 21-p 24$ & D3S734 & $4 \times 10^{-5}$ \\
3 p21-p24 & D3S232 & 0.0022 \\
$3 p 21$ & D3F15S2 & $1 \times 10^{-7}$ \\
$3 p 14-p 21$ & D3S32 & $8 \times 10^{-5}$ \\
$3 p 14.2-p 21$ & D3S2 & $9 \times 10^{-6}$ \\
$3 p 13$ & D3S642 & $4 \times 10^{-5}$ \\
$3 p 13$ & D3S3 & 0.1307 \\
\hline
\end{tabular}

adata from Latif et al (13); Probability that 3p loci in tumour DNA have the same heterozygosity as that of the normal population. *all significant at the 0.0023 level.

regions in lung cancer, 3p25, 3p21.3 and 3p14. Moreover, the 3 p14 region has been further defined in lung cancer by Yamakawa et al (24), and the 3p13-p21.1 region has been identified in uterine-cervical cancer (25) as a site of a putative TSG.

This study has identified two regions in SCCHN that are probably important in the development of squamous cell carcinoma of the head and neck (3p24-p25, 3p13), however, a larger number of patients will have to be studied with a bank of specific markers in these regions to determine their importance.

\section{Acknowledgements}

This research was supported by a grant from the North West Cancer Fund UK. The authors would like to thank Dr J Whittaker for advice and critically reading the manuscript. We acknowledge and thank David Alder, Department of Pathology University of Washington, Seattle for the use of the Idiogram Albums.

\section{References}

1. Lasko D, Cavenee W and Nordenskjold M: Loss of constitutional heterozygosity in human cancer. Ann Rev Genet 25: 281-314, 1991

2. Vogelstein B, Fearon ER, Kern SE, Hamilton SR, Preisinger AC, Nakamura Y and White R: Allelotype of colorectal carcinomas. Science 24: 207-210, 1988.

3. Delattre O, Law DJ, Remvikos Y, Sastre X, Feinberg AP, Olschwang S, Melot T, Salmon RJ, Validire P and Thomas G: Multiple genetic alterations in distal and proximal colorectal cancer. Lancet ii: 353-355, 1989. 
Table VII. Candidate genes on chromosome 3p.

Chromosomal location

\begin{tabular}{ll}
\hline 3pter-p21 & CCK \\
3pter-q21 & ACTL4 \\
3p26-p24 & IL5RA \\
3p25 & RAF1 \\
3p24.2-p21.2 & IMPDH2 \\
3p24.1-p22 & THRB \\
3p24 & RARB \\
3p24 & TOP2B \\
3p24-p22 & RAB5 \\
3p23-p22 & ACAA \\
3p23-p22 & GLB1 \\
3p22-p21 & ZNF35P \\
3p21.3 & ZNF52 \\
3p21.3 & ZNF64 \\
3p21.2-p21.1 & ITIH1 \\
3p21.2-p21.1 & ITIH3 \\
3p21.1 & ACY1 \\
3p21-p14 & PTPRG \\
3p14-q21 & SRML2
\end{tabular}

Name of gene locus

References from the Genome Data Base, John Hopkins University, School of Medicine, Baltimore, Maryland USA and the UK Human Genome Mapping Project Research Center, Harrow, Middlesex, UK

4. Eccles DM, Cranston G, Steel CM, Nakamura Y and Leonard RCF: Allele loss on chromosome 17 in human epithelial cancer. Oncogene 5: 1599-1601, 1990.

5. Russell SEH, Hickey GI, Lowry WS, White P and Atkinson RJ: Allele loss from chromosome 17 in ovarian cancer. Oncogene 5: 1581-1583, 1990.

6. Foulkes WD, Black DM, Stamp GWH, Solomon E and Trowsdale J: Very frequent loss of heterozygosity throughout chromosome 17 in sporadic ovarian carcinoma. Int $\mathbf{J}$ Cancer 54: 220-225, 1993.

7. Cunningham C, Dunlop MG, Wyllie AH and Bird CC: Deletion mapping in colorectal cancer of a putative tumour suppressor gene in 8p22-p21.3. Oncogene 8: 1391-1396, 1993.

8. Knowles MA, Shaw ME and Proctor AJ: Deletion mapping of chromosome 8 in cancers of the urinary bladder using restriction fragment length polymorphisms and microsatellite polymorphisms. Oncogene 8: 1357-1364, 1993.

9. Devilee P and Cornelisse CJ: Genetics of human breast cancer. Cancer Surv 9: 605-630, 1990.

10. Jin Y, Heim S, Mandahl N, Björklund A, Wennerberg J and Mitelman F: Multiple apparently unrelated clonal chromosome abnormalities in a squamous cell carcinoma of the tongue. Cancer Genet Cytogenet 32: 93-101, 1988.

11. Owens W, Field JK, Howard T and Stell PM: Multiple cytogenetic aberrations in squamous cell carcinoma of the head and neck. Eur J Cancer Oral Oncol 28B: 17-22, 1992.

12. Cowan JM: Cytogenetics in head and neck cancer. Otolaryngol Clin N Amer 25: 1073-1087, 1992.

13. Latif F, Fivash M, Glenn G, Tory K, Orcutt ML, Hampsch K, Delisio J, Lerman M, Cowan J, Beckett M and Weichselbaum R: Chromosome $3 p$ deletions in head and neck carcinomas: statistical ascertainment of allelic loss. Cancer Res 52: 14511456, 1992.

14. Allegra E, Garozzo A, Grillo A and Catalano GB: Cytogenetic alterations in laryngeal carcinomas. Arch Otolaryngol Head Neck Surg 118: 1320-1322, 1992

15. McKusick VA and Amberger JS: The morbid anatomy of the human genome: chromosomal location of mutations causing disease. J Med Genet 30: 1-26, 1993.
16. NIH/CEPH Collaborative Mapping Group: A comprehensive genetic linage map of the human genome. Science 258: 67-86, 1992.

17. Weissenbach J, Gyapay G, Dib C, Vignal A, Morissette J, Millasseau P, Vaysseix G and Lathrop M: A second-generation linkage map of the human genome. Nature 359: 794-801, 1992.

18. Thibodeau SN, Bren G and Schaid D: Microsatellite instability in cancer of the proximal colon. Science 260: 816-819, 1993.

19. Jones MJ, Yamakawa K and Nakamura Y: Isolation and characterization of 19 dinucleotide repeat polymorphisms on chromosome 3p. Hum Mol Genet 1: 131-133, 1992.

20. Kaplan EL and Meier P: Nonparametric estimation from complete observation. J Am Stat Assoc 53: 457-481, 1958.

21. Peto R, Pike MC, Armitage PE, Breslow NE, Cox DR, Howard SV, Mantel N, McPherson K, Peto J and Smith PG: Design and analysis of randomised clinical trials requiring prolonged observation of each patient. Br J Cancer 34: 585-612, 1976.

22. Jones AS: The management of early hypopharyngeal cancer: primary radiotherapy and salvage surgery. Clinical Otolaryngology 17: 545-549, 1992.

23. Hibi K, Takahashi T, Yamakawa K, Ueda R, Sekido Y, Ariyoshi Y, Suyama M, Takagi H, Nakamura Y and Takahashi T: Three distinct regions involved in $3 p$ deletion in human lung cancer. Oncogene 7: 445-449, 1992.

24. Yamakawa K, Takahashi T, Horio Y, Murata Y, Takahashi E, Hibi K, Yokoyama S, Ueda R, Takahashi T and Nakamura Y: Frequent homozygous deletions in lung cancer cell lines detected by a DNA marker located at 3p21.3-p22. Oncogene 8: 327-330, 1993.

25. Kohno T, Takayama H, Hamaguchi M, Takano H, Yamaguchi N, Tsuda H, Hirohashi S, Vissing H, Shimizu M, Oshimura M and Yokota J: Deletion mapping of chromosome 3p in human uterine cervical cancer. Oncogene 8: 1825-1832, 1993. 